\title{
Changes in Umbilical Artery Doppler Velocimetry After Betamethasone Administration in Pregnancies With Fetal Growth Retardation
}

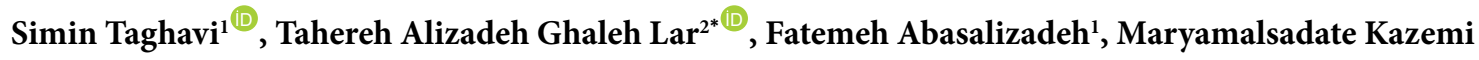 \\ Shishavan $^{3}$, Shamsi Abasalizadeh ${ }^{1}$, Sanaz Moosavi ${ }^{1}$, Zahra Fardi Azar ${ }^{1}$, Mojgan Mirghafourvand ${ }^{4}$
}

\begin{abstract}
Objectives: The administration of betamethasone is associated with increased placental vascular resistance results in the return of the diastolic flow. This study aimed to assess the changes in the flow velocity waveform (FVW) color Doppler in the umbilical artery after the administration of betamethasone in pregnancies with fetal growth retardation (FGR).

Materials and Methods: This descriptive-analytical research included all pregnant women who were referred to Al-Zahra teaching hospital and diagnosed with FGR. The eligibility criteria were the impaired umbilical artery FVW color Doppler, qualified for the administration of a fix-dosed Betamethasone, and no fetal abnormalities. The perinatologists performed the FVW color Doppler ultrasonography before and after the administration of betamethasone at intervals of 24, 48, and 96 hours and weeks 1 and 2. FVWs were obtained by pulsed-wave Doppler ultrasonography. Then, neonatal outcomes were recorded based on neonates' admission documents. Finally, one-way repeated measures ANOVA, Cochran's Q test, and paired-samples t-test were used to compare Doppler indices before and after betamethasone administration.

Results: The mean pulsatility index (PI) and resistance index (RI) of the umbilical artery showed a statistically significant reduction after the administration of betamethasone $(P<0.001)$. The measured umbilical artery PI at two weeks after drug administration predicted the neonatal intensive care unit admission $(P=0.042)$. Eventually, the results revealed no significant association between the amniotic fluid index (AFI) and betamethasone administration $(P=0.3)$.

Conclusions: In general, betamethasone administration improved the FVWs of the umbilical artery in pregnant women with fetal growth restriction while no association was found between the AFI and betamethasone administration.

Keywords: Betamethasone, Color Doppler, Fetal growth retardation, Umbilical artery
\end{abstract}

\section{Introduction}

Almost $3 \%$ of pregnancies and $5 \%$ of high-risk pregnancies are meddling with placental vascular resistance. This resistance is diagnosed with the absent end-diastolic flow (AEDF) in the color Doppler ultrasound of the umbilical artery $(1,2)$. flow velocity waveform (FVW) (FVW) color Doppler ultrasound in high-risk pregnancies with the AEDF of the umbilical artery can allow a $30 \%$ reduction in perinatal mortality and increased neonatal survival (3).

Fetal growth restriction before the 32 nd weeks of pregnancy could be identified with decreased amnion fluid, decreased diastolic velocity of the umbilical artery, and increased resistance in the fetal placenta flow (4). According to some studies $(5,6)$, this abnormal waveform velocity observed in the umbilical artery color Doppler ultrasound is associated with defective oxygenation, partial access to intraarterial material, fetal growth restriction, and high fetal mortality (30\%). In severe cases, this increased resistance is characterized by the absence or reversal of the diastolic end flow velocity of the umbilical artery. Reduced oxygenation leads to lactic acid production and impaired fetal myocardial function (5-7). Placental corticotrophin-releasing hormone (CRH) is a potent vasodilator in the placental fetal bloodstream that may interfere with placental blood flow regulation (8). In addition, the ingestion of corticosteroids during pregnancy, which accelerates fetal maturation and improves the perinatal outcome, can regulate the expression and secretion of CRH from the placenta, and treatment through corticosteroids may potentially change the blood flow (9).

One of the beneficial treatments for women affected by preterm labor is corticosteroids (10), which are recommended for women less than 34 weeks of pregnancy (11). According to $(12,13)$, the administration of a full course of corticosteroids significantly improves neonatal 
Key messages

- Betamethasone use can be associated with improved umbilical artery resistance. This is because improvements in umbilical artery resistance allow the physician to let the pregnancy continue for more prolonged periods and prevent preterm birth and its complications and thus reduces the costs for the family and the health care system.

outcomes (betamethasone $12 \mathrm{mg}$ every 24 hours up to 2 dosages and dexamethasone $6 \mathrm{mg}$ every 12 hours up to 4 dosages). Previous research showed that betamethasonehas extremely fewer side effects compared to dexamethasone (14). Further, evidence suggests that prenatal benefits, as well as maternal and neonatal complications are not associated with multiple courses of corticosteroids compared to a single course (15). The National Institutes of Health Consensus Development Panel concluded that the full benefits of taking corticosteroids appear in infants 24 hours after the treatment. The effects of corticosteroid administration will fix up to 7 days (16). The beneficial effects of betamethasone may be temporarily limited to 7 days and thus most physicians prescribe betamethasone every 7 days (17).

However, other studies reported that the repeated use of betamethasone could have harmful effects such as increased chorioamnionitis, reduced birth weight, and increased risk of fetal deaths $(18,19)$. Premature infants are more prone to hypoglycemia, jaundice, body temperature instability, and most importantly, respiratory disorders compared to full-term infants (10). This proneness increases the probability of respiratory distress, along with hypoxia and a rise in the $\mathrm{pH}$ of the umbilical cord and even infant mortality (10). Due to the benefits of corticosteroids in the fetal lung maturation, the administration of these drugs is well accepted in many medical centers. Corticosteroids are associated with decreased fetal heart rate variability in addition to decreased fetal and respiratory movements (20). Recent evidence demonstrated that the recurrent end-diastolic flow and change in frequency and the duration of waveform velocity could be anticipated after betamethasone administration to pregnant women with increased placental resistance and the AEDF in the umbilical artery color Doppler ultrasonography (21).

The results of previous studies revealed a different scope of the effect of betamethasone on the color Doppler. Cochrane Reviews showed that corticosteroid administration resulted in the reversal of the end-diastolic flow in pregnant women with fetal growth restrictions and the AEDF or REDF of the umbilical artery (21). Edward et al reported a reversal of the end-diastolic flow after the administration of Betamethasone, which continued for 3 days, but there was no evidence of the benefits for the fetus (22). Wallace and Baker also reported the reversal of the end-diastolic flow and decreased placental vascular resistance in $70 \%$ of their study participants and observed a transient return during the end-diastolic flow in the 19 to 28 weeks of gestation (21). However, Cohlen et al and Rotmensch et al reported "no change" in fetal vascular resistance $(23,24)$.

It is worthy to emphasize the transpassing of hormones and agents into the placenta, helping the fetus to thrive. Any disruption in critical agent delivery may cause perinatal and postpartum complications thus maintaining a proper blood flow is necessary for good fetal outcomes. Most studies on betamethasone in pregnancy focused on its effects on pulmonary maturity as it is frequently administered to women with high-risk pregnancy and fetal growth restriction for fetal lung maturation. Although most studies addressing the effect of betamethasone on umbilical color Doppler indices reported contradictory results, plenty of them showed the beneficial effects of betamethasone on preferable placental blood flow. Considering these effects, the current study aimed to assess the variability of the betamethasone administration effect on Doppler ultrasonography indices and examine how they change after drug administration.

\section{Materials and Methods}

Study Design and Participants

This descriptive-analytical study was conducted on pregnant women who referred to Al-Zahra teaching hospital, which is a referral center for high-risk pregnancies, in the northwest of Iran. All pregnant women with fetal growth restrictions referring from April 2018 to March 2019 were evaluated in this study.

\section{Study Population and Sampling}

The current study investigated all pregnant women with fetal growth retardation (FGR), the gestational age of 24 weeks, six days to 33 weeks, and six days, and impaired umbilical artery Doppler who were registered in the highrisk clinic of Al-Zahra teaching center in Tabriz.

The inclusion criteria were women with a singleton pregnancy and fetal growth restrictions, the pregnancy age of 24 weeks and six days to 33 weeks and 6 days, and the impaired arterial color Doppler and those indicated for the administration of betamethasone with permanent dosages (12 mg with an interval of 24 hours up to 2 dosages). On the other hand, pregnancies with a fetal abnormality were excluded from the study.

Moreover, this study included no data for the women who gave birth to a child for two weeks after receiving betamethasone in the final analysis. First, the qualified mother was briefed about the procedure and reason for the research, and patients' permissions were obtained to use their information for the research. Then, the participant was asked to fill out the demographic form. A midwife scheduled the participant for color Doppler ultrasonography in the feto-maternal clinic of the Al-Zahra 
teaching hospital. The on-duty perinatologist performing the Doppler ultra-sonography was unaware of the participation status of the patients. Additionally, the same perinatologist performed the follow-up ultrasonography as scheduled after betamethasone administration. In addition, the trained midwife gathered the information in a document for each patient.

\section{Data Collection Tool}

A demographic characteristic form and a checklist were used to record FVW color Doppler indices such as the mean pulsatility index (PI) and resistance index (RI) of the umbilical artery, AEDF, REDF, the amniotic fluid index (AFI) and neonatal outcomes. The group of the attending perinatologist determined the content and face validity of the checklist. All Doppler indices were measured at predefined intervals, namely, before betamethasone administration and 24, 48, and 96 hours after drug administration, and in the last two weeks of gestation.

\section{Statistical Method}

One-way repeated measures ANOVA and the post hoc tests were used to compare Doppler indices before and after betamethasone administration. In addition, the Cochran's Q test and paired-samples t-test were applied to examine the changes in AEDF and REDF and to compare mean AFI changes at two intervals, respectively. Further, logistic regression analysis was used to predict neonatal outcomes. $P$ values less than 0.05 were considered statistically significant and IBM SPSS (21) was used for data analysis.

\section{Results}

This study evaluated all 80 women with eligible pregnancies based on study criteria, who were referred or attended the perinatal clinic at Al-Zahra teaching hospital. The mean (M) age and its standard deviation (SD) were 29.3 and 0.68 and the median gestation age was 32 weeks (interquartile range $=4.75$ ). Furthermore, most participants were nulliparous or in their second pregnancy (39\% and 29\%, respectively) and preeclampsia was confirmed in $14 \%$ of participants (Table 1 ).

\section{AFI, PI, and RI}

A one-way repeated measures ANOVA was conducted to compare AFI before betamethasone administration, as well as 24,48 , and 96 hours after drug administration. There were no significant differences between repeated measurements (Wilks Lambda $=0.59$, F $(3,8)=1.79$, $P=0.3)$.

However, there was a significant change in PI (Wilks Lambda $=0.38, \mathrm{~F}(3,57)=30.83, P<0.001)$. Post hoc tests using the Bonferroni correction revealed that betamethasone elicited a slight reduction in umbilical artery PI from pre-drug injection to 24 hours later (1.37, $95 \% \mathrm{CI}=1.31,1.43$ vs. 1.25 and $95 \% \mathrm{CI}=1.19,1.31$,
Table 1. Sociodemographic and Obstetric Characteristics of Pregnant Women With Fetal Growth Retardation

\begin{tabular}{|c|c|}
\hline Variable & Number (\%) \\
\hline Age (y) & $29.3(6.1)^{*}$ \\
\hline Gestational age & $30.9(4.2)^{*}$ \\
\hline Delivery week & $35.6(2.5)^{*}$ \\
\hline \multicolumn{2}{|l|}{ Type of previous delivery } \\
\hline \multicolumn{2}{|l|}{ Cesarean section } \\
\hline Yes & $36(45.0)$ \\
\hline \multicolumn{2}{|l|}{ Normal vaginal delivery } \\
\hline Yes & $15(18.8)$ \\
\hline \multicolumn{2}{|l|}{ Using medicine in pregnancy } \\
\hline Yes & $16(20.0)$ \\
\hline No & $64(80.0)$ \\
\hline \multicolumn{2}{|l|}{ Smoking } \\
\hline Yes & $1(1.3)$ \\
\hline \multicolumn{2}{|l|}{ Gravidity } \\
\hline 1 & $31(38.8)$ \\
\hline 2 & $24(30.0)$ \\
\hline 3 and more & $25(31.4)$ \\
\hline \multicolumn{2}{|l|}{ Parity } \\
\hline 0 & $39(48.8)$ \\
\hline 1 & $29(36.3)$ \\
\hline 2 and more & $12(15.1)$ \\
\hline \multicolumn{2}{|l|}{ Abortion } \\
\hline 0 & $62(77.5)$ \\
\hline 1 & $9(11.3)$ \\
\hline 2 and more & $9(11.4)$ \\
\hline \multicolumn{2}{|l|}{ Alive child } \\
\hline 0 & $37(46.3)$ \\
\hline 1 & $33(41.3)$ \\
\hline 2 and more & $10(12.5)$ \\
\hline \multicolumn{2}{|l|}{ Dead child } \\
\hline 0 & $77(96.3)$ \\
\hline 1 and more & $3(3.8)$ \\
\hline Body mass index $\left(\mathrm{kg} / \mathrm{cm}^{2}\right)$ & $29.6(4.8)^{*}$ \\
\hline Preeclampsia & $14(17.5)$ \\
\hline Spontaneous labor & $17(21.3)$ \\
\hline Pregnancy diabetes & $1(1.3)$ \\
\hline Chronic hypertension & $15(18.8)$ \\
\hline Total number of women & 80 \\
\hline
\end{tabular}

*Data were reported based on the mean (standard deviation).

respectively), which was statistically significant $(P<$ 0.001). This reduction remained consistently significant after 48 and 96 hours $(P<0.001)$. However, no statistically significant reduction was observed after 72 hours and umbilical PI on the 4 th day was not significantly different from the third day measurement (mean difference $=0.05$, $95 \% \mathrm{CI}=-0.40$ to 0.09 )

Data were examined to assess significant changes in umbilical artery RI during the process. Based on the findings (Figure 1), there was a significant diminution in umbilical artery RI, (Wilks Lambda $=0.62$, F $(3,56)$ $=11.07, P<0.001)$ and using the Bonferroni correction, 
post hoc tests revealed that betamethasone represented a reduction in umbilical artery PI from pre-drug injection to 24 hours later (Mean difference $=0.04,95 \% \mathrm{CI}=0.01$, $0.06)$ which was statistically significant $(P<0.001)$. Similar to the umbilical artery PI, no statistically significant reduction was found after 72 hours $(P=1.00)$.

A paired-samples $t$ test was conducted to compare mean AFI changes in the first 96 hours $(\mathrm{M}=7.42, \mathrm{SD}=$ 3.13) after betamethasone with mean AFI in the last two weeks $(\mathrm{M}=7.96, \mathrm{SD}=3.30)$ of gestation. The results revealed no statistically significant difference between the measurements of these periods ( $95 \% \mathrm{CI}=-1.47$ to 0.47 ).

\section{AEDF}

Data on 77 participants were analyzed to examine whether EDF appears following betamethasone administration after 24, 48, 96 hours, and weeks 1 and 2. Based on the results of the Cochran's Q test, there was no statistically significant difference in the proportion of participants whose EDF disappeared after betamethasone $(\chi 2(3)=$ 3.78, $P=0.28)$.

\section{REDF}

REDF was recorded in 2 out of 77 participants before betamethasone administration. Cochran's Q test demonstrated no statistically significant change in the proportion of participants with REDF after betamethasone administration $(\chi 2(3)=2.40, P=0.49)$.

\section{Neonatal Outcomes}

\section{Umbilical Cord $\mathrm{pH}$}

Based on study results, there was no significant linear correlation between umbilical cord $\mathrm{pH}$ and umbilical RI and PI before betamethasone administration $(P=0.74$ and $P=0.20$, respectively), nor two weeks after drug administration.

\section{Neonatal Intensive Care Unit Admission}

Logistic regression was performed to ascertain the associations of age, body mass index, chronic hypertension, and preeclampsia measured two weeks after drug administration and fetus growth perceptible with the likelihood of neonate admission to ICU. It should be noted that the logistic regression model was statistically significant $(\chi 2(8)=16.91, P=0.03)$. The model explained $41.0 \%$ (Nagelkerke $R^{2}$ ) of the variance in getting admitted to neonatal intensive care unit (NICU) and correctly classified $66.0 \%$ of cases. There was a negative predicting relationship between umbilical cord PI, which was measured 2 weeks after betamethasone administration, and the likelihood of being admitted to the NICU. For every percent increase in umbilical cord PI, it was $6 \%$ more likely to be admitted to NICU (odds ratio $=1.06$, $95 \% \mathrm{CI}=-1.002$ to $1.137, P=0.042$ ). Eventually, there was no significant association between other predictors (Table 2).

\section{Discussion}

The results of this study showed that betamethasone administration improved color Doppler indices including the mean PI and RI of the umbilical artery. Placental terminal villi affect FVWs and are one of the main determinants of resistance in the fetal placental vascular flow, and evidence represented that pregnancies with the AEDF have fewer third-generation villi in placental arterioles. According to some studies, AEDF in the umbilical artery reflects increased resistance in placental blood flow (25-27). An association was reported between AEDF in the umbilical artery with abnormal FVWs and fetal hypoxia, acidemia, and FGR, and it simultaneously increases prenatal mortality. Therefore, using FVW color Doppler ultrasound to diagnose the AEDF of the umbilical artery in high-risk pregnancies may help in treatments for

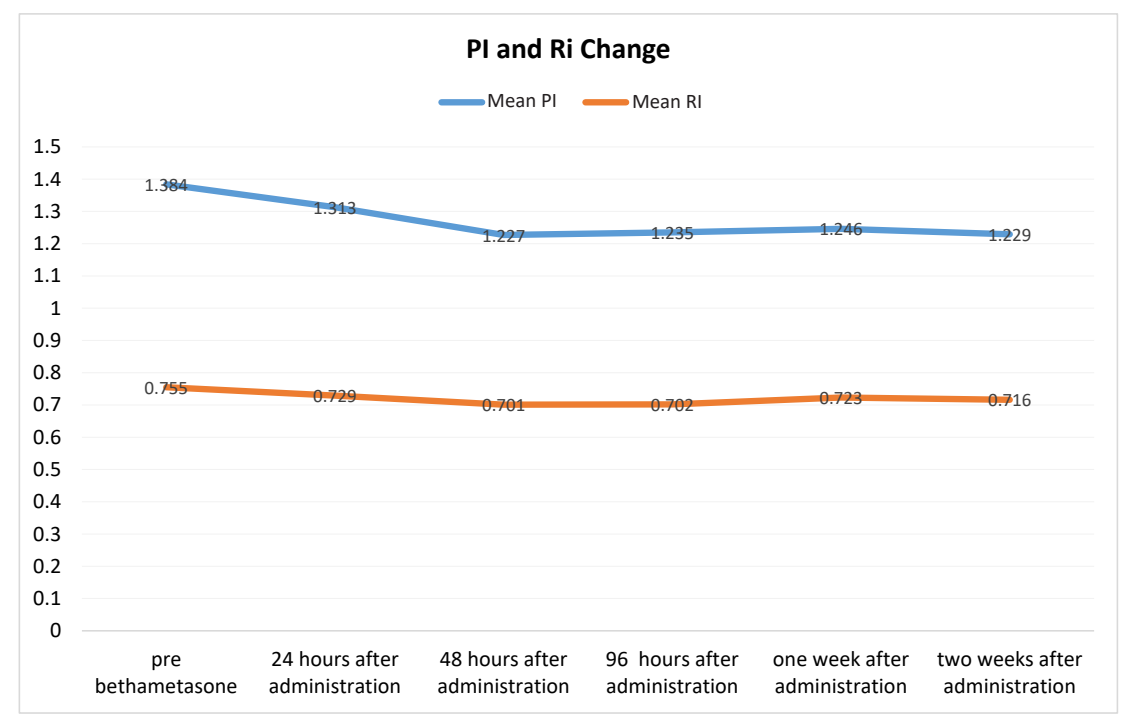

Figure 1. Changes of Pulsatility Index and Resistance Index of Umbilical Artery. 
Table 2. Predictors of Hospital Admission in the Neonatal Intensive Care Unit

\begin{tabular}{lcc}
\hline Variable & $\mathbf{B}(95 \% \mathrm{Cl})$ & $\boldsymbol{P}$ Value \\
\hline $\begin{array}{l}\text { Resistance index of umbilical } \\
\text { artery in second week }\end{array}$ & $0.0(0.0$ to 1090.8$)$ & 0.260 \\
$\begin{array}{l}\text { Pulsatility index of umbilical } \\
\text { artery in second week }\end{array}$ & $1.0(1.0$ to 1.1$)$ & 0.04 \\
$\begin{array}{l}\text { Body mass index } \\
\text { Cesarean section }\end{array}$ & $0.8(0.7$ to 1.0$)$ & 0.258 \\
$\begin{array}{l}\text { Preeclamsia } \\
\text { Chronic hypertension }\end{array}$ & $1.1(0.1$ to 12.1$)$ & 0.900 \\
$\begin{array}{l}\text { Fetal weight percentile before } \\
\text { betamethasone administration }\end{array}$ & $0.7(0.5$ to 1.1$)$ & 0.189 .189 \\
\hline
\end{tabular}

better fetal outcomes $(28,29)$.

In most pregnancies with umbilical artery AEDF, diastolic flow reappears after the administration of corticosteroids in the early days of the administration, which may not sustain until the end of pregnancy. To avoid false confidence by observing normal FVWs, color Doppler monitoring is suggested to remedy any clinical concerns (3). Our findings showed a statistically significant decrease in the mean PI and RI of the umbilical artery. Although no direct evidence was found to explain the decrease in vascular resistance, $\mathrm{CRH}$ secretion from the placenta, which is an essential regulator of the fetal placental blood flow through the nitric oxide pathway, may be associated with the vasodilation after betamethasone administration $(8,30)$. Exogenous corticosteroid suppresses the secretion of $\mathrm{CRH}$ in the hypothalamus and increases both the $\mathrm{CRH}$ gene expression and $\mathrm{CRH}$ secretion in the placenta $(9,31)$. Moreover, betamethasone induces nitric oxide synthesis via $\mathrm{CRH}$ secretion. Besides, it has an independent vasodilator effect on nitric oxide deficient vessels although it has no such effect on healthy vessels (23,32-34).

Simchen et al conducted a study on 19 fetuses with growth restriction, and six healthy fetuses as controls aimed at finding the fetal cardiovascular response to corticosteroids. The result showed that the end-diastolic flow reappeared after 24 hours following steroid injection in ten fetuses that had AEDF although there was no significant difference in the mean PI between the steroid and control groups. The baseline PI was significantly higher in fetuses with growth restriction compared to healthy ones (35).

In another study, Piazze et al focused on thirtysix pregnant women who received the full dose betamethasone. They assessed umbilical artery PI, middle cerebral artery PI, and uterine artery RI with Doppler before betamethasone administration and after 46 and 96 hours. The umbilical artery PI decreased transiently and the change was unstable. Likewise, Chitrit et al included 26 pregnant women with preterm labor and normal placental uterine artery resistance in their study. Umbilical and cerebral artery Doppler were performed before and during 2 and 4 days, and one week after betamethasone administration and the results demonstrated a transient and unstable decrease in PI $(36,37)$. In the study by Cohlen et al, 18 women with preterm labor were given Betamethasone and then Doppler measurements were performed before and 24 and 72 hours after the second dose. Based on the findings, the PI showed no significant change (23). This instability may occur because steroids function better for healthy pregnancies compared to pregnancies with severe fetal growth restrictions. In this regard, evidence suggests that the type- 2 enzyme 11-B-hydroxy steroid-dehydrogenase, which generally prevents maternal steroids from entering the fetus, does not work in fetuses with severe growth restrictions. Compared to the healthy fetuses at the same gestational age, who are well adapted to placental glucocorticoid metabolites, this enzyme dysfunctionality causes higher fetal exposure to maternal steroids $(38,39)$.

Wallace and Baker (21) performed a pre- and postbetamethasone administration ultrasonography of the umbilical artery in pregnant women with increased placental vascular resistance and observed umbilical artery AEDF. Additionally, a transient decrease in the end- diastolic flow was observed at 19 to 28 weeks of gestation. Further, the diastolic flow of the umbilical artery reappeared after the administration of betamethasone within 24 hours with low resistance in the umbilical artery flow. This effect prolonged for 2-7 days (mid-day was also three days). Ohlsson et al also reported an increase in mean arterial blood pressure after dexamethasone administration in very low birth weight fetuses (40). In vitro and animal studies showed that glucocorticosteroids increase fetal arterial blood pressure and this elevation in blood pressure leads to an increase in the blood flow of umbilical veins and arteries and results in return of enddiastolic blood flow (41-43).

In the study of Edward et al, diastolic end flow reversal was found in $71 \%$ of pregnant mothers at three days (median of 1 to 10 days). However, in studies of Senat et al (44), Cohlen et al (23), and Rotmensch et al (24), no changes were observed in vascular resistance. This discrepancy with our findings is probably due to the short duration of follow-ups after betamethasone in these studies.

The leading cause of AEDF in this study was FGR or maternal hypertension, considering that the applied medications for hypertension in pregnant women, including labetalol, increased the PI of the umbilical artery rather than reducing it (22).

The results of this study also showed that the PI measured two weeks after the administration of betamethasone predicts neonatal admission to NICU. Studies are limited to NICU administration associated with umbilical artery PI. This study mostly focused on studies that assessed the effect of betamethasone on both umbilical artery PI and 


\section{NICU admission.}

In their cross-sectional study aiming at modeling the color Doppler flow and waveform intraplacental circulation in fetuses with growth restriction, Rotmensch et al included 192 women with a healthy pregnancy within the age range of 26-41 weeks and 29 women with fetal growth restrictions at the same gestational age. The results showed that the end-diastolic flow of the umbilical artery was absent in 8 (27.6\%) women with fetal growth restrictions and neonatal Apgar was 8 and 5 out of 10, respectively. Hypoxia and respiratory distress were the causes of neonatal mortality (24).

In a clinical trial, Haji Seid Javadi et al evaluated the effect of betamethasone in delayed preterm pregnancies on neonatal respiratory failure and compared betamethasone with normal saline. They reported that admission to NICU was higher in the infants of the normal saline group although this increase was not statistically significant (45).

Similarly, Ventolini et al conducted a clinical trial with a large sample size to examine the effect of betamethasone on the development of respiratory disorders in neonates. The result showed that the rate of admission to the NICU was significantly higher in the control group that received no betamethasone (46). In a double-blind clinical trial conducted by Mansouri et al, the administration of betamethasone reduced the 24-hour NICU stay (47). On the other hand, Saymari et al reported no significant effect of betamethasone concerning a decrease in NICU admission (15).

The results of our study represented no statistically significant change in AFI before betamethasone administration and serial measurements after drug injection. In the study of Khazardoost et al, no significant changes were also observed in the AFI before and after betamethasone administration (48). Contrarily Jackson et al found a significant decrease in amniotic fluid levels 48 hours after betamethasone administration (49). Rotmensch et al reported the same results and confirmed those of Jackson's study (24). The findings of these studies might differ from our results because of the limited amniotic fluid in follow-up examinations.

Nevertheless, the underlying cause of amniotic fluid loss after betamethasone administration has not been entirely determined yet. The disseminated expression of corticosteroid receptors in different parts of the brain (i.e., the cortical and middle parts) may cause the neurological suppression of the fetus. This low activity of the brain may justify the decrease in breathing movements and the heart rate in the fetus. Finally, reduced breathing may lead to decreased amnion fluid excretion and affect amniotic fluid levels (50).

\section{Limitations}

The present study has some limitations. The results cannot be generalized to twin pregnancies with growth restrictions or pregnancies longer than 33 weeks and 6 days. Thus, we recommend designing similar studies with pregnant women from the early stages of fetal growth restrictions at any age of the pregnancy. Controlling for fetal weight percentiles, fetal biometric growth criteria, perinatal outcomes, and other arterial and venous Doppler velocimetry changes of the fetoplacental unit should also be considered in this regard.

In addition, it is recommended that future studies include predictive variables to assess inadequate responses to steroids. Factors such as the evidence of severe placental injury measured by ultrasonography, fetal intestinal echogenicity, and multiple-drug treatment for severe preeclampsia are of great importance in this respect.

On the other hand, the strength of the study was examining the effect of betamethasone on placental circulation in pregnancies with FGR compared to previous studies. Most previous studies tracked the effect of betamethasone on the fetus for seven days while this study followed changes for up to two weeks after the administration of Betamethasone.

\section{Conclusions}

In general, betamethasone administration improved FVW Doppler indices including the mean pulsatility and resistance indices of the umbilical artery in pregnant women with fetal growth restriction while no association was found between the AFI and betamethasone administration.

Fetal growth restriction is associated with poor outcomes for both the mother and fetus in most medical centers. On the other hand, betamethasone use can be associated with improved umbilical artery resistance. This is because improvements in umbilical artery resistance allow the physician to let the pregnancy continue for more prolonged periods and prevent preterm birth and its complications and thus reduces the costs for the family and the health care system.

\section{Conflict of Interests}

Authors declare that they have no conflict of interests.

\section{Ethical Issues}

This study was conducted after obtaining necessary permits from the Ethics Committee of the Vice-chancellor for the Research of Tabriz University of Medical Sciences (Ethics code: IR.TBZMED.REC.1397.1071) and the Head of Al-Zahra hospital in Tabriz. All ethics were respected in this study. Considering the private nature of the questions, the provided answers were only reviewed by the researcher in order to build confidence in participants, and it was unnecessary to write the names on the questionnaires.

\section{Financial Support}

The Research Center of Tabriz University of Medical Science funded this research. The funding center had no role in the design, analysis, or writing of this article. 


\section{Acknowledgments}

The researcher and her colleagues express their gratitude to the Research Center of Tabriz University of Medical Sciences, the clinic of Al-Zahra hospital, the Health Centers of Tabriz, and all women who helped us in this research.

\section{References}

1. Thompson RS, Trudinger BJ, Cook CM. Doppler ultrasound waveform indices: $\mathrm{A} / \mathrm{B}$ ratio, pulsatility index and Pourcelot ratio. Br J Obstet Gynaecol. 1988;95(6):581588. doi:10.1111/j.1471-0528.1988.tb09487.x

2. Beattie RB, Dornan JC. Antenatal screening for intrauterine growth retardation with umbilical artery Doppler ultrasonography. BMJ. 1989;298(6674):631-635. doi:10.1136/bmj.298.6674.631

3. Neilson JP, Alfirevic Z. Doppler ultrasound in high risk pregnancies. In: Neilson JP, Crowther CA, Hodnett ED, Hofmeyr GJ, eds. Pregnancy and childbirth module of the Cochrane database of systematic reviews [CD ROM and online]. Cochrane Collaboration; issue 1. Oxford: Update Software, 1998.

4. Kingdom J, Smith G. Diagnosis and management of IUGR. In: Kingdom J, Baker P, eds. Intrauterine Growth Restriction. London: Springer-Verlag; 2000:257-273. doi:10.1007/978-1-4471-0735-4_13

5. Marconi AM, Cetin I, Ferrazzi E, Ferrari MM, Pardi G, Battaglia FC. Lactate metabolism in normal and growthretarded human fetuses. Pediatr Res. 1990;28(6):652-656. doi:10.1203/00006450-199012000-00022

6. Nicolaides KH, Bilardo CM, Soothill PW, Campbell S. Absence of end diastolic frequencies in umbilical artery: a sign of fetal hypoxia and acidosis. BMJ. 1988;297(6655):1026-1027. doi:10.1136/bmj.297.6655.1026

7. Soothill PW, Nicolaides KH, Bilardo K, Hackett GA, Campbell S. Utero-placental blood velocity resistance index and umbilical venous $\mathrm{pO} 2, \mathrm{pCO} 2, \mathrm{pH}$, lactate and erythroblast count in growth-retarded fetuses. Fetal Ther. 1986;1(4):176-179. doi:10.1159/000262265

8. Challis JR, Matthews SG, Van Meir C, Ramirez MM. Current topic: the placental corticotrophin-releasing hormoneadrenocorticotrophin axis. Placenta. 1995;16(6):481-502. doi:10.1016/s0143-4004(05)80001-3

9. Robinson BG, Emanuel RL, Frim DM, Majzoub JA. Glucocorticoid stimulates expression of corticotropinreleasing hormone gene in human placenta. Proc Natl Acad Sci U S A. 1988;85(14):5244-5248. doi:10.1073/ pnas.85.14.5244

10. Dudell GG, Jain L. Hypoxic respiratory failure in the late preterm infant. Clin Perinatol. 2006;33(4):803-830; abstract viii-ix. doi:10.1016/j.clp.2006.09.006

11. Vidaeff AC, Ramin SM, Gilstrap LC, 3rd, Alcorn JL. In vitro quantification of dexamethasone-induced surfactant protein B expression in human lung cells. J Matern Fetal Neonatal Med. 2004;15(3):155-159. doi:10.1080/14767050 410001668248

12. National Institutes of Health. Report of the Consensus Development Conference on the Effect of Corticosteroids for Fetal Maturation on Perinatal Outcomes (NIH Publication No. 95-3784). Bethesda, MD: National Institutes of Health, National Institute of Child Health and Human Development; 1994.
13. Liggins GC, Howie RN. A controlled trial of antepartum glucocorticoid treatment for prevention of the respiratory distress syndrome in premature infants. Pediatrics. 1972;50(4):515-525.

14. Ballard PL, Ballard RA. Scientific basis and therapeutic regimens for use of antenatal glucocorticoids. Am J Obstet Gynecol. 1995;173(1):254-262. doi:10.1016/00029378(95)90210-4

15. Saymari F, Zand Vakili F, Rezaie M, Mansori M, Afkhamzadeh A. Comparing the impact of prescribing one dose or two doses of injecting betamethasone for pregnant women on preterm infants outcomes. The Horizon of Medical Sciences. 2015;21(1):53-58. doi:10.18869/acadpub. hms.21.1.53

16. Effect of corticosteroids for fetal maturation on perinatal outcomes. NIH Consensus Development Panel on the Effect of Corticosteroids for Fetal Maturation on Perinatal Outcomes. JAMA. 1995;273(5):413-418. doi:10.1001/ jama.1995.03520290065031

17. Quinlivan JA, Evans SF, Dunlop SA, Beazley LD, Newnham JP. Use of corticosteroids by Australian obstetricians--a survey of clinical practice. Aust N Z J Obstet Gynaecol. 1998;38(1):1-7. doi:10.1111/j.1479-828x.1998.tb02947.x

18. Vermillion ST, Soper DE, Chasedunn-Roark J. Neonatal sepsis after betamethasone administration to patients with preterm premature rupture of membranes. Am J Obstet Gynecol. 1999;181(2):320-327. doi:10.1016/s00029378(99)70555-7

19. Banks BA, Cnaan A, Morgan MA, et al. Multiple courses of antenatal corticosteroids and outcome of premature neonates. North American Thyrotropin-Releasing Hormone Study Group. Am J Obstet Gynecol. 1999;181(3):709-717. doi:10.1016/s0002-9378(99)70517-x

20. Derks JB, Mulder EJ, Visser GH. The effects of maternal betamethasone administration on the fetus. Br J Obstet Gynaecol. 1995;102(1):40-46. doi:10.1111/j.1471-0528.1995.tb09024.x

21. Wallace EM, Baker LS. Effect of antenatal betamethasone administration on placental vascular resistance. Lancet. 1999;353(9162):1404-1407. doi:10.1016/s01406736(98)08229-4

22. Edwards A, Baker LS, Wallace EM. Changes in umbilical artery flow velocity waveforms following maternal administration of betamethasone. Placenta. 2003;24(1):1216. doi:10.1053/plac.2002.0874

23. Cohlen BJ, Stigter RH, Derks JB, Mulder EJ, Visser GH. Absence of significant hemodynamic changes in the fetus following maternal betamethasone administration. Ultrasound Obstet Gynecol. 1996;8(4):252-255. doi:10.1046/j.1469-0705.1996.08040252.x

24. Rotmensch S, Liberati M, Celentano C, et al. The effect of betamethasone on fetal biophysical activities and Doppler velocimetry of umbilical and middle cerebral arteries. Acta Obstet Gynecol Scand. 1999;78(9):768-773.

25. Kingdom JC, Burrell SJ, Kaufmann P. Pathology and clinical implications of abnormal umbilical artery Doppler waveforms. Ultrasound Obstet Gynecol. 1997;9(4):271286. doi:10.1046/j.1469-0705.1997.09040271.x

26. Giles WB, Trudinger BJ, Baird PJ. Fetal umbilical artery flow velocity waveforms and placental resistance: pathological correlation. Br J Obstet Gynaecol. 1985;92(1):31-38. doi:10.1111/j.1471-0528.1985.tb01045.x

27. McCowan LM, Mullen BM, Ritchie K. Umbilical artery 
flow velocity waveforms and the placental vascular bed. Am J Obstet Gynecol. 1987;157(4 Pt 1):900-902. doi:10.1016/ s0002-9378(87)80082-0

28. Nicolaides KH, Bilardo CM, Soothill PW, Campbell S. Absence of end diastolic frequencies in umbilical artery: a sign of fetal hypoxia and acidosis. BMJ. 1988;297(6655):1026-1027. doi:10.1136/bmj.297.6655.1026

29. Beattie RB, Dornan JC. Antenatal screening for intrauterine growth retardation with umbilical artery Doppler ultrasonography. BMJ. 1989;298(6674):631-635. doi:10.1136/bmj.298.6674.631

30. Clifton VL, Read MA, Leitch IM, et al. Corticotropinreleasing hormone-induced vasodilatation in the human fetal-placental circulation: involvement of the nitric oxide-cyclic guanosine 3',5'-monophosphate-mediated pathway. J Clin Endocrinol Metab. 1995;80(10):2888-2893. doi:10.1210/jcem.80.10.7559870

31. Marinoni E, Korebrits C, Di Iorio R, Cosmi EV, Challis JR. Effect of betamethasone in vivo on placental corticotropin-releasing hormone in human pregnancy. Am J Obstet Gynecol. 1998;178(4):770-778. doi:10.1016/s00029378(98)70490-9

32. Giles W, O'Callaghan S, Boura A, Walters W. Reduction in human fetal umbilical-placental vascular resistance by glyceryl trinitrate. Lancet. 1992;340(8823):856. doi:10.1016/0140-6736(92)92737-z

33. Bisits A, Madsen G, McLean M, O'Callaghan S, Smith R, Giles W. Corticotropin-releasing hormone: a biochemical predictor of preterm delivery in a pilot randomized trial of the treatment of preterm labor. Am J Obstet Gynecol. 1998;178(4):862-866. doi:10.1016/s0002-9378(98)60503-2

34. Giles W, O'Callaghan S, Read M, Gude N, King R, Brennecke S. Placental nitric oxide synthase activity and abnormal umbilical artery flow velocity waveforms. Obstet Gynecol. 1997;89(1):49-52. doi:10.1016/s0029-7844(96)00371-7

35. Simchen MJ, Alkazaleh F, Adamson SL, et al. The fetal cardiovascular response to antenatal steroids in severe earlyonset intrauterine growth restriction. Am J Obstet Gynecol. 2004;190(2):296-304. doi:10.1016/j.ajog.2003.08.011

36. Piazze JJ, Anceschi MM, La Torre R, Amici F, Maranghi L, Cosmi EV. Effect of antenatal betamethasone therapy on maternal-fetal Doppler velocimetry. Early Hum Dev. 2001;60(3):225-232. doi:10.1016/s0378-3782(00)00120-1

37. Chitrit Y, Caubel P, Herrero R, Schwinte AL, Guillaumin D, Boulanger MC. Effects of maternal dexamethasone administration on fetal Doppler flow velocity waveforms. BJOG. 2000;107(4):501-507. doi:10.1111/j.1471-0528.2000. tb13269.x

38. McTernan CL, Draper N, Nicholson H, et al. Reduced placental 11beta-hydroxysteroid dehydrogenase type 2 mRNA levels in human pregnancies complicated by intrauterine growth restriction: an analysis of possible mechanisms. J Clin Endocrinol Metab. 2001;86(10):49794983. doi:10.1210/jcem.86.10.7893

39. Shams M, Kilby MD, Somerset DA, et al. 11Betahydroxysteroid dehydrogenase type 2 in human pregnancy and reduced expression in intrauterine growth restriction. Hum Reprod. 1998;13(4):799-804. doi:10.1093/ humrep/13.4.799

40. Ohlsson A, Bottu J, Govan J, Ryan ML, Myhr T, Fong K. The effect of dexamethasone on time averaged mean velocity in the middle cerebral artery in very low birth weight infants. Eur J Pediatr. 1994;153(5):363-366. doi:10.1007/bf01956420

41. Bennet L, Kozuma S, McGarrigle HH, Hanson MA. Temporal changes in fetal cardiovascular, behavioural, metabolic and endocrine responses to maternally administered dexamethasone in the late gestation fetal sheep. Br J Obstet Gynaecol. 1999;106(4):331-339. doi:10.1111/j.1471-0528.1999.tb08270.x

42. Derks JB, Giussani DA, Jenkins SL, et al. A comparative study of cardiovascular, endocrine and behavioural effects of betamethasone and dexamethasone administration to fetal sheep. J Physiol. 1997;499(Pt 1):217-226. doi:10.1113/ jphysiol.1997.sp021922

43. Sun K, Adamson SL, Yang K, Challis JRG. Interconversion of cortisol and cortisone by $11 \beta$-hydroxysteroid dehydrogenases type 1 and 2 in the perfused human placenta. Placenta. 1999;20(1):13-19. doi:10.1053/ plac. 1998.0352

44. Senat MV, Ville Y. Effect of steroids on arterial Doppler in intrauterine growth retardation fetuses. Fetal Diagn Ther. 2000;15(1):36-40. doi:10.1159/000020972

45. Haji Seid Javadi E, Movahed F, Baricany A, Jafari M. Effect of betamethasone on neonatal respiratory failure in late preterm pregnancies. Journal of Gorgan University of Medical Sciences. 2016;17(4):16-20. [Persian].

46. Ventolini G, Neiger R, Mathews L, Adragna N, Belcastro M. Incidence of respiratory disorders in neonates born between 34 and 36 weeks of gestation following exposure to antenatal corticosteroids between 24 and 34 weeks of gestation. Am J Perinatol. 2008;25(2):79-83. doi:10.1055/s-2007-1022470

47. Mansouri M, Seyedolshohadaei F, Company F, Setare S, Mazhari S. Effect of antenatal betamethasone on prevention of respiratory distress syndrome among neonates with gestational age of 35-36 weeks. Journal of Gorgan University of Medical Sciences. 2010;12(3):18-23. [Persian].

48. Khazardoost S, Pooransari P, Mirzamoradi M. The effect of betamethasone on fetal movement, biophysical profile and fetal circulation in preterm fetuses. Life Sci J. 2012;9(4):1990-1992.

49. Jackson JR, Kleeman S, Doerzbacher M, Lambers DS. The effect of glucocorticosteroid administration on fetal movements and biophysical profile scores in normal pregnancies. J Matern Fetal Neonatal Med. 2003;13(1):5053. doi:10.1080/jmf.13.1.50.53

50. Deren O, Karaer C, Onderoglu L, Yigit N, Durukan T, Bahado-Singh RO. The effect of steroids on the biophysical profile and Doppler indices of umbilical and middle cerebral arteries in healthy preterm fetuses. Eur J Obstet Gynecol Reprod Biol. 2001;99(1):72-76. doi:10.1016/s03012115(01)00367-0

(c) 2020 The Author(s); This is an open-access article distributed under the terms of the Creative Commons Attribution License (http:// creativecommons.org/licenses/by/4.0), which permits unrestricted use, distribution, and reproduction in any medium, provided the original work is properly cited. 